\title{
A MULTI SCALE APPROACH FOR THE GROUND MOTION MODELLING IN URBAN AREAS
}

\author{
Alessandro Tombari ${ }^{1}$ and Pierfrancesco Cacciola ${ }^{2}$ \\ ${ }^{1}$ University of Brighton \\ Cockcroft Building Lewes Road BN2 4GJ, UK \\ e-mail: a.tombari@brighton.ac.uk \\ ${ }^{2}$ University of Brighton \\ Cockcroft Building Lewes Road BN2 4GJ, UK \\ p.cacciola@brighton.ac.uk
}

\begin{abstract}
Seismic ground motion in urban environment is generally modified by the presence of buildings. This phenomenon, referred to as Site-City Interaction, is mainly due to the radiated waves emitted through the soil by vibrating structures. Therefore, the urban seismic wavefield is altered from the free field motion with zones of higher and lower energy, i.e. largest and smaller ground motion amplitude, respectively. Because of the complexity of the phenomenon, modelling and simulations of large dense cities might be performed with large computational costs.
\end{abstract}


In this paper, a random urban wavefield is obtained through a hierarchical multi-scale approach that defines representative areas obtained by homogenization of cluster of buildings at local-scale. An equivalent single oscillator is hence derived for each representative areas by considering uncertain parameters such as the fundamental period. Therefore, a proposed model combining discrete model and wave propagation model is used to evaluate the interactions among the several representative areas at city-scale to derive the seismic ground motion map for urban areas in terms of 50\% fractile peak acceleration. Monte Carlo Simulation study is performed for validation purposes. Finally, the proposed framework is applied to a real urban area using data from LIDAR maps.

Keywords: Seismic city-soil interaction, urban environment, stochastic analysis. 


\section{INTRODUCTION}

In the last decades, global population growth has resulted in the rapid development of densely urbanized and compact areas. In earthquake-prone regions, these urban areas are exposed to high seismic risk because of the high concentration of population, strategic infrastructures and business activities. Current seismic design maps determine the free-field peak acceleration, namely the motion of the ground surface undisturbed by any man-made structures. Conversely, numerous studies have pointed out the influence of buildings strongly affects the free field motion due to the energy that is transmitted back to the soil by the vibrating structures as identified by Housner [1], Wong and Trifunac [2] and Wirgin and Bard [3], Ditommaso et al.[5]; successively, the multiple interactions between vibrating buildings and soil, named as site-city interaction, has been studied by Clouteau and Aubry [6], Kham et al. [6], Isbililiroglu et al. [7], Wirgin [8], Taddei and Müller [9]. Therefore, the consequent ground-motion acceleration at the free-field currently used for designing civil engineering structures can be significantly different from the predicted one inside the urban area. Recently, Cacciola and Tombari [10] introduced a ground motion stochastic model in terms of closed-form power spectral density to represent the seismic action around one or more buildings to be incorporated in a design process accounting for the urban effect. Because of the complex nature of the city-soil interaction problems, simplified models are generally used to take into account the modification of the ground motion in the urban environment; Guéguen et al. [11] showed the effect of the city can be accounted for by modelling the structures as simple oscillators. Tsogka and Wirgin [12] used homogenized blocks to study the seismic response in an idealized city. A homogenization method has been used also by Boutin and Roussillon [13] to determine the multiple interactions between buildings. Groby et al. [14] studied the seismic response of idealized 2D cities using a continuum viscoelastic medium. Ghergu and Ionescu [15] studied the collective behavior of the 
buildings in a city like environment through a partial differential equation coupled with an ordinary differential equation through a special class of boundary conditions. Two-dimensional FE shear walls have been used by Coronado et al. [16] to simulate a section of the small village of Vathia in Greece.

In this paper, a hierarchical multi-scale approach to model the ground motion in urban areas is proposed. At mesoscale level, the effect of each cluster of buildings is derived through a homogenization approach based on the strategy used in acoustic to determine the perturbations induced in a large main structure by several small substructures attached to it (Soize [17], Strass and Feit, [18], Friis and Ohlrich, [19] and [20]). Then, at macroscale level, the ground motion in the urban environment is derived through a wave propagation model (Morse and Ingard, [21]). The proposed multiscale approach is hence applied to a cluster of 1000 buildings with uniform and log-normal random distribution of fundamental periods to show the effectiveness of the method. Monte Carlo finite element simulation is performed for validation purposes. Finally, the proposed framework is applied to real urban area using data from LIDAR maps.

\section{PROBLEM POSITION}

Consider the 2D idealized portion of a city depicted in Figure 1 undergoing ground motion vibration modelled as zero mean Gaussian stationary vector process at the bedrock, $\mathbf{U}_{\mathrm{b}}$ fully defined by the knowledge of the power spectral density matrix $\mathbf{S}_{\mathrm{ub}}(\omega)$. Let assume for simplicity sake the structures and soil behaving linearly. 


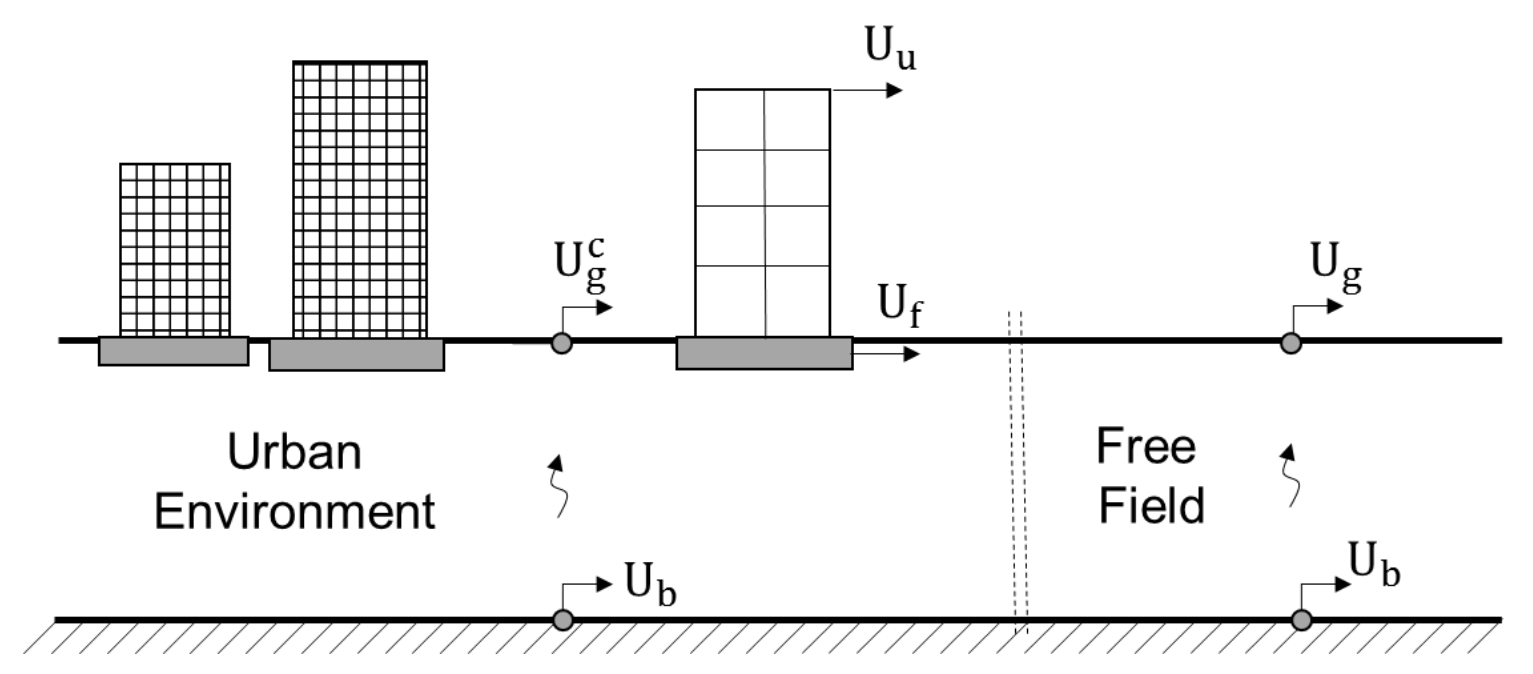

Figure 1 Sketch of an urban environment under ground motion

Under the above hypothesis the dynamic motion of the coupled urban system (after a pertinent FE discretization) is governed by the following equation in terms of absolute displacements in the frequency domain

$$
\mathbf{M} \ddot{\mathbf{U}}(\omega)+\widetilde{\mathbf{K}}(\omega) \mathbf{U}(\omega)=\widetilde{\mathbf{K}}(\omega) \mathbf{T} \mathbf{U}_{\mathrm{b}}(\omega)
$$

where $\mathbf{M}$ and $\widetilde{\mathbf{K}}(\omega)$ are the $n_{d} \times n_{d}$ mass and complex stiffness matrix of the coupled system, $\mathbf{U}$ is the vector listing the displacements of the $n_{d}$ degrees of freedom and $\mathbf{T}$ is the frequencyindependent matrix given by

$$
\mathbf{T}=-\operatorname{Re}\{\widetilde{\mathbf{K}}(\omega)\}^{-1} \mathbf{k}_{\mathrm{b}}
$$

with $\mathbf{k}_{\mathrm{b}}$ is the matrix of order $n_{d} \times n_{b}\left(n_{b}=\right.$ number of degrees of freedom at the bedrock) accounting for the forces induced in the soil due a unitary displacement of each individual joint of the bedrock while the others are imposed to be zero. Eq. (1) can be also written in expanded form as follow (see Figure 1) 


$$
\begin{aligned}
& {\left[\begin{array}{ccc}
\mathbf{M}_{\mathrm{u}} & 0 & 0 \\
0 & \mathbf{M}_{\mathrm{f}} & 0 \\
0 & 0 & \mathbf{M}_{\mathrm{s}}
\end{array}\right]\left[\begin{array}{c}
\ddot{\mathbf{U}}_{\mathrm{u}}(\omega) \\
\ddot{\mathbf{U}}_{\mathrm{f}}(\omega) \\
\ddot{\mathbf{U}}_{\mathrm{g}}^{\mathrm{c}}(\omega)
\end{array}\right]+\left[\begin{array}{ccc}
\widetilde{\mathbf{K}}_{\mathrm{u}}(\omega) & \widetilde{\mathbf{K}}_{\mathrm{u}, \mathrm{f}}(\omega) & 0 \\
\widetilde{\mathbf{K}}_{\mathrm{f}, \mathrm{u}}(\omega) & \widetilde{\mathbf{K}}_{\mathrm{f}}(\omega) & \widetilde{\mathbf{K}}_{\mathrm{s}, \mathrm{f}}(\omega) \\
0 & \widetilde{\mathbf{K}}_{\mathrm{f}, \mathrm{s}}(\omega) & \widetilde{\mathbf{K}}_{\mathrm{s}}(\omega)
\end{array}\right]\left[\begin{array}{c}
\mathbf{U}_{\mathrm{u}}(\omega) \\
\mathbf{U}_{\mathrm{f}}(\omega) \\
\mathbf{U}_{\mathrm{g}}^{\mathrm{c}}(\omega)
\end{array}\right]=} \\
& {\left[\begin{array}{ccc}
\widetilde{\mathbf{K}}_{\mathrm{u}}(\omega) & \widetilde{\mathbf{K}}_{\mathrm{u}, \mathrm{f}}(\omega) & 0 \\
\widetilde{\mathbf{K}}_{\mathrm{f}, \mathrm{u}}(\omega) & \widetilde{\mathbf{K}}_{\mathrm{f}}(\omega) & \widetilde{\mathbf{K}}_{\mathrm{s}, \mathrm{f}}(\omega) \\
0 & \widetilde{\mathbf{K}}_{\mathrm{f}, \mathrm{s}}(\omega) & \widetilde{\mathbf{K}}_{\mathrm{s}}(\omega)
\end{array}\right] \mathbf{T U}_{\mathrm{b}}(\omega)}
\end{aligned}
$$

where $\mathbf{M}_{\mathrm{j}}$, and $\mathbf{K}_{\mathrm{j}}(\omega)$ are the mass and the complex stiffness submatrices in which the index $\mathrm{j}=$ $\mathrm{u}, \mathrm{f}, \mathrm{s}$ is used for indicating the buildings superstructure in the urban environment, the building foundations and the soil, respectively. The vector $\mathbf{U}_{\mathrm{j}}$ for $\mathrm{j}=\mathrm{u}, \mathrm{f}, \mathrm{s}$ lists the displacements degrees of freedom. Note that Eq. (3) highlights the unknown vector $\ddot{\mathbf{U}}_{\mathrm{g}}^{\mathrm{c}}$ that represents the ground motion of the soil deposit within the urban environment. Therefore, the ground motion at a specific location within the urban environment can be readily extracted by the response power spectral density matrix given by the following equation

$$
\mathbf{S}_{\mathbf{U}}(\omega)=\mathbf{H}(\omega) \mathbf{S}_{\mathrm{U}_{\mathrm{b}}}(\omega) \mathbf{H}^{*}(\omega)
$$

where the asterisk in Eq. (4) stands for transpose complex conjugate, and the matrix $\mathbf{H}(\omega)$ is given by

$$
\mathbf{H}(\omega)=\left(\widetilde{\mathbf{K}}(\omega)-\omega^{2} \mathbf{M}\right)^{-1} \widetilde{\mathbf{K}}(\omega) \mathbf{T}
$$

From Eq. (5) elements of the response power spectral density matrix $\mathbf{G}_{\mathbf{U}}(\omega)$, and in particular the elements pertinent to the degrees of freedom of the soil at the surface, are in general function of both the soil and the structures within the urban environment. Therefore, the seismic wave field on the surface is affected by the presence of the buildings that can be interpreted as vibrating obstacles, inducing scattering to the ground motion waves and will be different from the traditionally used free field ground motion that neglects the presence of vibrating structures. In 
the case of ground motion at the bedrock modelled as monocorrelated Gaussian stochastic process Eq. (1) is reduced to

$$
\mathbf{M} \ddot{\mathbf{U}}(\omega)+\widetilde{\mathbf{K}}(\omega) \mathbf{U}(\omega)=\widetilde{\mathbf{K}}(\omega) \tau U_{\mathrm{b}}(\omega)
$$

where $\boldsymbol{\tau}$ is the incidence vector. As a consequence the response power spectral density matrix is given by

$$
\mathbf{S}_{\mathbf{U}}(\omega)=\mathbf{H}(\omega) \mathbf{H}^{*}(\omega) \mathrm{S}_{\mathrm{U}_{\mathrm{b}}}(\omega)
$$

where $S_{U_{b}}(\omega)$ is the power spectral density function of the ground motion at the bedrock. Although the approach of modelling a large portion of a city might be attractive as it faces directly the problem to determine the ground motion in the urban environment by extracting the pertinent elements from the response matrix, from a practical point of view it is unfeasible due its computational demand and for the unavoidable epistemic uncertainties involved in the model. Therefore, an alternative approach is proposed in this paper and presented in the following sections.

\section{MULTISCALE APPROACH}

The method proposed of determining the ground surface motion in urban areas is a multiscale method that comprises two models, i.e. a soil-structure and a wave propagation model, in a hierarchical scheme. The following sections describe the proposed multiscale approach from microscale (single buildings) to mesoscale (cluster of buildings) and macroscale (city).

\subsection{Definition of a representative region}

The first step of the proposed approach consists in determining the distribution of the structural frequencies within a representative region called elementary representative block (ERB). This region (Boutin and Roussillon, [13]) is similar to the "representative volume element" 
used in soil mechanics (see, e.g. Hill, [22]) to describe a typical part of the whole mixture on average. Scale techniques (see, e.g. Ostoja-Starzewski, [23]) can be used to define the ERB. For wave propagation problems, the scale separation between the microscale $(d$, size of the building foundation) and the mesoscale ( $L$, size of the ERB) is achieved when $L / d \rightarrow \infty$, conversely a scale effect is created. The city can be seen as divided in several non-overlapping ERBs each one with a different distribution of the structural natural frequencies. In the next section, to reduce the multiple interactions between structures through the soil, a homogenization procedure of the ERB is proposed.

\subsection{Urbanization effect induced by resonant structures}

Consider the structural discrete system depicted in Figure 2; the equation governing the motion of the system in terms of absolute displacements in the frequency domain is determined as:

$$
\left(\widetilde{\mathbf{K}}(\omega)-\omega^{2} \mathbf{M}\right) \mathbf{U}(\omega)=\widetilde{\mathbf{K}}(\omega) \boldsymbol{\tau} \mathrm{U}_{\mathrm{FIM}}(\omega)
$$

where $U_{\text {FIM }}(\omega)$ is the input motion at the base of the foundation, usually referred to as foundation input motion, namely the motion of the massless foundation under seismic loading. Therefore, from Eq. (1) the solution in its expanded form is given by

$$
\left[\begin{array}{c}
\mathrm{U}(\omega) \\
\mathrm{U}_{\mathrm{f}}(\omega)
\end{array}\right]=\left(\left[\begin{array}{cc}
\tilde{\mathrm{k}}_{\mathrm{str}} & -\tilde{\mathrm{k}}_{\mathrm{str}} \\
-\tilde{\mathrm{k}}_{\mathrm{str}} & \tilde{\mathrm{k}}_{\mathrm{str}}+\tilde{\mathrm{k}}_{\mathrm{SSI}}(\omega)
\end{array}\right]-\omega^{2}\left[\begin{array}{cc}
\mathrm{m}_{\mathrm{str}} & 0 \\
0 & \mathrm{~m}_{\mathrm{f}}
\end{array}\right]\right)^{-1}\left[\begin{array}{c}
0 \\
\tilde{\mathrm{k}}_{\mathrm{SSI}}(\omega)
\end{array}\right] \mathrm{U}_{\mathrm{FIM}}(\omega)
$$

whereas the hypothesis of hysteretic damping is retained, i.e. $\tilde{\mathrm{k}}_{\mathrm{str}}=\mathrm{k}_{\mathrm{str}}(1+i \eta), i=\sqrt{-1}$ is the imaginary unit and $\eta$ is the loss factor. Furthermore, the dependence of $\tilde{\mathrm{k}}_{\mathrm{SSI}}$ from the circular frequency $\omega$ is hereinafter omitted for simplicity sake and determined through a static approach, without affecting the generality of the formulation. Therefore, the frequency transfer function of the foundation displacement, $\mathrm{H}_{\mathrm{f}}(\omega)$, defined as the ratio between the foundation displacement, $\mathrm{U}_{\mathrm{f}}(\omega)$, and the foundation input motion, $\mathrm{U}_{\mathrm{FIM}}(\omega)$, is readily derived as follows: 


$$
\mathrm{H}_{\mathrm{f}}\left(\omega, \widetilde{\omega}_{0}\right)=\frac{\mathrm{U}_{\mathrm{f}}\left(\omega, \widetilde{\omega}_{0}\right)}{\mathrm{U}_{\mathrm{FIM}}(\omega)}=\frac{\widetilde{\omega}_{\mathrm{f}}^{2}\left(\omega^{2}-\widetilde{\omega}_{0}^{2}\right)}{\left(\widetilde{\omega}_{0}^{2}-\omega^{2}\right)\left(\omega^{2}-\widetilde{\omega}_{\mathrm{f}}^{2}\right)+\omega^{2} \widetilde{\omega}_{0}^{2}\left(\mathrm{~m}_{\mathrm{str}} / \mathrm{m}_{\mathrm{f}}\right)}-1
$$

in which

$$
\omega_{0}^{2}=\left(\frac{k_{\mathrm{str}}}{m_{\mathrm{str}}}\right)
$$

is the squared circular natural frequency of the fixed base SDOF superstructure and,

$$
\omega_{\mathrm{f}}^{2}=\left(\frac{k_{\mathrm{SSI}}}{m_{\mathrm{f}}}\right)
$$

is the squared circular natural frequency of the soil-foundation system. In this paper, the foundation input motion, $\mathrm{U}_{\mathrm{FIM}}(\omega)$ is considered approximated as free field motion, i.e. $\mathrm{U}_{\mathrm{FIM}}(\omega) \cong$ $\mathrm{H}_{\text {soil }}(\omega) \mathrm{U}_{\mathrm{g}}(\omega)$, where $\mathrm{H}_{\text {soil }}(\omega)$ is the transfer function of the soil deposit. During an earthquake event, the seismic waves propagating in an urban environment cause the vibration of a multitude of $\mathrm{n}$ buildings along with the soil where they are founded. This scenario can be seen as a large mass (i.e. the soil deposit) to which are attached $n$ small resonators or sprung masses (i.e. the buildings); in the context of vibroacustic problems, it is conventionally adopted that the total driving-point impedance is given by the sum of each individual spring mass impedance (see, e.g. Soize, [17], Strasberg and Feit, [18]). 


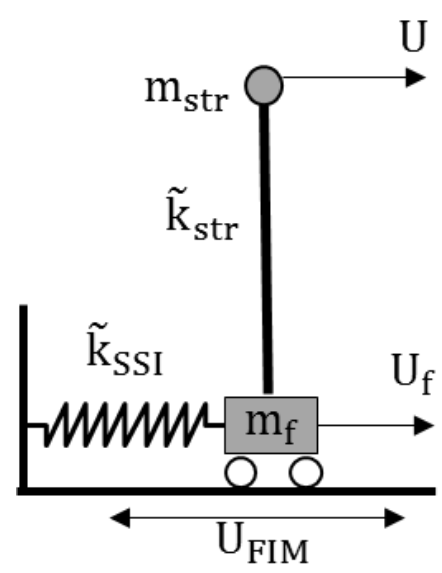

Figure 2 Structural discrete model by considering soil-structure interaction effects

Similarly, the equivalent transfer function of a cluster of $n$ buildings on the ground surface within the elementary representing block $(\mathrm{ERB})$ is obtained as the sum of the foundation transfer function of each building as follows:

$$
\mathrm{H}_{\mathrm{f}}^{c l}(\omega)=\sum_{i=1}^{n} \mathrm{H}_{\mathrm{f}, \mathrm{i}}\left(\omega, \widetilde{\omega}_{0, \mathrm{i}}\right)=\sum_{i=1}^{n} \frac{\widetilde{\omega}_{\mathrm{f}}^{2}\left(\omega^{2}-\widetilde{\omega}_{0, i}^{2}\right)}{\left(\widetilde{\omega}_{0, i}^{2}-\omega^{2}\right)\left(\omega^{2}-\widetilde{\omega}_{\mathrm{f}}^{2}\right)+\omega^{2} \widetilde{\omega}_{0, i}^{2} \beta}-1
$$

where $\beta=\left(\mathrm{m}_{\mathrm{str}} / \mathrm{m}_{\mathrm{f}}\right)$ and $\omega_{\mathrm{f}}$ are assumed as identical for each of the $n$ buildings, for simplicity sake. The aim of this formulation is to derive an equivalent local oscillator (Soize, [17], Friis and Ohlrich, [19]) as an average of the building impedances over the whole ERB (Boutin and Rousillon, [13]). Closed-form evaluation of Eq. (13) is obtained when the natural frequencies of the buildings, $\omega_{0, \mathrm{i}}$, for $i=1, \ldots, n$, are closely spaced; therefore, Eq. (13) can be approximated by an integral in the range $\omega_{0}^{-} \leq \omega_{0, \mathrm{i}} \leq \omega_{0}^{+}$, where $\widetilde{\omega}_{0, j}^{-}$and $\widetilde{\omega}_{0, j}^{+}$are the respectively the lower and upper limit of the considered interval of natural frequencies, as follows:

$$
\mathrm{H}_{\mathrm{f}}^{c l}(\omega)=\sum_{i=1}^{n} \mathrm{H}_{\mathrm{f}, \mathrm{i}}\left(\omega, \widetilde{\omega}_{0, \mathrm{i}}\right) \cong \frac{n}{\widetilde{\omega}_{0}^{+}-\widetilde{\omega}_{0}^{-}} \int_{\widetilde{\omega}_{0}^{-}}^{\widetilde{\omega}^{+}} \mathrm{H}_{\mathrm{f}}\left(\omega, \widetilde{\omega}_{0}\right) d \widetilde{\omega}_{0}
$$

The solution of Eq. (14) can be obtained in closed-form solution as

$$
\mathrm{H}_{\mathrm{f}}^{c l}(\omega) \cong \frac{n}{\widetilde{\omega}_{0}^{+}-\widetilde{\omega}_{0}^{-}}\left(\mathrm{L}_{\mathrm{f}}\left(\omega, \widetilde{\omega}_{0}^{+}\right)-\mathrm{L}_{\mathrm{f}}\left(\omega, \widetilde{\omega}_{0}^{-}\right)\right)
$$


where $L_{f}$ is the indefinite integral of $H_{f}\left(\omega, \widetilde{\omega}_{0}\right)$, i.e. $L_{f}=\int H_{f}\left(\omega, \widetilde{\omega}_{0}\right) d \widetilde{\omega}_{0}$, and it can be expressed as follows

$$
\mathrm{L}_{\mathrm{f}}\left(\omega, \widetilde{\omega}_{0}\right)=\left(\frac{-\widetilde{\omega}_{\mathrm{f}}^{2}}{\omega^{2}+\beta \omega^{2}-\widetilde{\omega}_{\mathrm{f}}^{2}}-1\right) \widetilde{\omega}_{0}+\frac{\left(\beta \widetilde{\omega}_{\mathrm{f}}^{2} \omega^{3}\right) \tan ^{-1}\left(\frac{\widetilde{\omega}_{0}\left(\omega^{2}+\beta \omega^{2}-\widetilde{\omega}_{\mathrm{f}}^{2}\right)^{0.5}}{\omega\left(\widetilde{\omega}_{\mathrm{f}}^{2}-\omega^{2}\right)^{0.5}}\right)}{\left(\widetilde{\omega}_{\mathrm{f}}^{2}-\omega^{2}\right)^{0.5}\left(\omega^{2}+\beta \omega^{2}-\widetilde{\omega}_{\mathrm{f}}^{2}\right)^{1.5}}
$$

Therefore, Eqs (15) and (16) can be used to derive a homogenization model to simulate the urbanization effect within a cluster of buildings. In case of non-uniform distribution of the natural frequencies of the buildings , the numerical integral in Eq. (14) have to be reformulated in order to account for a non-uniform grid; therefore, a piece-wise integration approach can be applied as follows

$$
\mathrm{H}_{\mathrm{f}}^{c l}(\omega)=\sum_{j=1}^{m} \frac{n}{\widetilde{\omega}_{0, j}^{+}-\widetilde{\omega}_{0, j}^{-}} \int_{\widetilde{\omega}_{0, j}^{-}}^{\widetilde{\omega}_{0}^{+}} \mathrm{H}_{\mathrm{f}}\left(\omega, \widetilde{\omega}_{0}\right) d \omega_{0}
$$

and hence:

$$
\mathrm{H}_{\mathrm{f}}^{c l}(\omega) \cong \sum_{j=1}^{m} \frac{n}{\widetilde{\omega}_{0, j}^{+}-\widetilde{\omega}_{0, j}^{-}}\left(\mathrm{L}_{\mathrm{f}}\left(\omega, \widetilde{\omega}_{0, j}^{+}\right)-\mathrm{L}_{\mathrm{f}}\left(\omega, \widetilde{\omega}_{0, j}^{-}\right)\right)
$$

where $\widetilde{\omega}_{0, j}^{-}$and $\widetilde{\omega}_{0, j}^{+}$are the respectively the lower and upper limit of the jth out of the $\mathrm{m}$ subintervals in which the total domain is divided. Eq. (18) represents the equivalent transfer function of the cluster of buildings.

\subsection{Homogenization model for a random distribution of the structural frequencies}

The previous procedure can be extended for the case of random distribution of the structural natural frequencies within the elementary representing block. Let the structural natural frequency, $\omega_{0}$, be a random variable described by its probability density function $p_{\omega_{0}}\left(\omega_{0}\right)$. The equivalent transfer function of the cluster, $\mathrm{H}_{\mathrm{f}}^{c l}\left(\omega, \omega_{0}\right)$, is a family of frequency-dependent functions depending on the random variable $\omega_{0}$ : for a specific $\omega, H_{f}^{c l}\left(\omega, \omega_{0}\right)$ is a random variable. 
Statistical properties can be derived from the knowledge of $\mathrm{H}_{\mathrm{f}}^{c l}\left(\omega, \omega_{0}\right)$; the average cluster effect on the soil is derived though the definition of expectation of the function, $\mathrm{E}\left[\mathrm{H}_{\mathrm{f}}^{c l}\left(\omega, \omega_{0}\right)\right]$, as follows:

$$
\mathrm{E}\left[\mathrm{H}_{\mathrm{f}}^{c l}\left(\omega, \omega_{0}\right)\right]=\int_{-\infty}^{\infty} \sum_{i=1}^{n} \mathrm{H}_{\mathrm{f}, \mathrm{i}}\left(\omega, \widetilde{\omega}_{0, \mathrm{i}}\right) p_{\omega_{0}}\left(\omega_{0}\right) d \omega_{0}
$$

where, the tilde, $:$ :., is used to indicate the hysteretic complex behavior. By using the linearity of the expectation, Eq. (19) is rewritten as follows:

$$
\mathrm{E}\left[\mathrm{H}_{\mathrm{f}}^{c l}\left(\omega, \omega_{0}\right)\right]=\sum_{i=1}^{n} \int_{-\infty}^{\infty} \mathrm{H}_{\mathrm{f}, \mathrm{i}}\left(\omega, \widetilde{\omega}_{0, \mathrm{i}}\right) p_{\omega_{0}}\left(\omega_{0}\right) d \omega_{0}
$$

Consider the random distribution of structural periods, $p_{\omega_{0}}\left(\omega_{0}\right)$, modelled trough an uniform distribution:

$$
p_{\omega_{0}}=\left\{\begin{array}{cl}
\frac{1}{\omega_{0}^{+}-\omega_{0}^{-}}, & \omega_{0}^{-} \leq \omega_{0} \leq \omega_{0}^{+} \\
0, & \text { otherwise }
\end{array}\right.
$$

Eq. (20) can be rewritten as follows:

$$
\mathrm{E}\left[\mathrm{H}_{\mathrm{f}}^{c l}\left(\omega, \omega_{0}\right)\right]=\frac{1}{\widetilde{\omega}_{0}^{+}-\widetilde{\omega}_{0}^{-}} \sum_{i=1}^{n} \int_{\widetilde{\omega}_{0}^{-}}^{\widetilde{\omega}_{+}^{+}} \mathrm{H}_{\mathrm{f}}\left(\omega, \widetilde{\omega}_{0}\right) d \omega_{0}
$$

and, therefore:

$$
\mathrm{E}\left[\mathrm{H}_{\mathrm{f}}^{c l}\left(\omega, \omega_{0}\right)\right]=\frac{n}{\widetilde{\omega}_{0}^{+}-\widetilde{\omega}_{0}^{-}} \int_{\widetilde{\omega}_{0}^{-}}^{\widetilde{\omega}_{+}^{+}} \mathrm{H}_{\mathrm{f}}\left(\omega, \widetilde{\omega}_{0}\right) d \widetilde{\omega}_{0}
$$

which is equivalent with Eq. (14) and, hence, which solution is given by Eq. (15) obtained for a deterministic linear distribution of the structural periods. For a non-uniform distribution, the expectation is applied to Eq. (18) and it yields:

$$
\mathrm{E}\left[\mathrm{H}_{\mathrm{f}}^{c l}\left(\omega, \omega_{0}\right)\right] \cong \int_{-\infty}^{\infty} \sum_{j=1}^{m} \frac{n}{\widetilde{\omega}_{0, j}^{+}-\widetilde{\omega}_{0, j}^{-}}\left(\mathrm{L}_{\mathrm{f}}\left(\omega, \widetilde{\omega}_{0, j}^{+}\right)-\mathrm{L}_{\mathrm{f}}\left(\omega, \widetilde{\omega}_{0, j}^{-}\right)\right) p_{\omega_{0}}\left(\omega_{0}\right) d \widetilde{\omega}_{0}
$$

and hence, by using the linearity of the expectation: 


$$
\mathrm{E}\left[\mathrm{H}_{\mathrm{f}}^{c l}(\omega)\right] \cong \sum_{j=1}^{m} \frac{n}{\widetilde{\omega}_{0, j}^{+}-\widetilde{\omega}_{0, j}^{-}}\left(\mathrm{L}_{\mathrm{f}}\left(\omega, \widetilde{\omega}_{0, j}^{+}\right)-\mathrm{L}_{\mathrm{f}}\left(\omega, \widetilde{\omega}_{0, j}^{-}\right)\right) \int_{-\infty}^{\infty} p_{\omega_{0}}\left(\omega_{0}\right) d \widetilde{\omega}_{0}
$$

The integral in Eq. (25) is by definition of probability density function, equal to the unity:

$$
\mathrm{E}\left[\mathrm{H}_{\mathrm{f}}^{c l}\left(\omega, \omega_{0}\right)\right] \cong \sum_{j=1}^{m} \frac{n}{\widetilde{\omega}_{0, j}^{+}-\widetilde{\omega}_{0, j}^{-}}\left(\mathrm{L}_{\mathrm{f}}\left(\omega, \widetilde{\omega}_{0, j}^{+}\right)-\mathrm{L}_{\mathrm{f}}\left(\omega, \widetilde{\omega}_{0, j}^{-}\right)\right)
$$

In accordance with the discretization procedure in Pfaffinger [24], Eq. (26) represents the expectation of the equivalent local oscillator transfer function of the cluster effect for a given random distribution of the structural frequencies. The conditional power spectral density, $\mathrm{S}_{\mathrm{U}_{\mathrm{f}}^{c l}}\left(\omega \mid \omega_{0}\right)$, of the response of the equivalent local oscillator is approximated by the equation:

$$
\mathrm{S}_{\mathrm{U}_{\mathrm{f}}^{c l}}\left(\omega \mid \omega_{0}\right)=\left(\mathrm{H}_{\mathrm{f}}^{c l}\left(\omega, \omega_{0}\right)\right)^{*} \mathrm{H}_{\mathrm{f}}^{c l}\left(\omega, \omega_{0}\right)\left|\mathrm{H}_{\text {soil }}(\omega)\right|^{2} \mathrm{~S}_{\mathrm{W}}
$$

where | is the absolute value operator and, $S_{W}$ is the power spectral density of the ground motion at the bedrock modelled as a Gaussian white noise process. Therefore, the power spectral density of the response of the cluster is:

$$
\mathrm{S}_{\mathrm{U}_{\mathrm{f}}^{c l}}(\omega)=\int_{0}^{\infty} \mathrm{S}_{\mathrm{U}_{\mathrm{f}}^{c l}}\left(\omega \mid \omega_{0}\right) p_{\omega_{0}}\left(\omega_{0}\right) d \omega_{0}
$$

Therefore, by using Eq. (27), and using the discretization approach of Eq. (17), Eq. (28) is rewritten as follows:

$$
\mathrm{S}_{\mathrm{U}_{\mathrm{f}}^{c l}}(\omega)=\sum_{j=1}^{m}\left(\frac{n}{\widetilde{\omega}_{0, j}^{+}-\widetilde{\omega}_{0, j}^{-}}\right)^{2}\left|\mathrm{~L}_{\mathrm{f}}\left(\omega, \widetilde{\omega}_{0, j}^{+}\right)-\mathrm{L}_{\mathrm{f}}\left(\omega, \widetilde{\omega}_{0, j}^{-}\right)\right|^{2}\left|\mathrm{H}_{\text {soil }}(\omega)\right|^{2} \mathrm{~S}_{\mathrm{W}}
$$

in which the summation indicates the energy of the of the transfer function of the equivalent oscillator to simulate the cluster of buildings and $\left|H_{\text {soil }}(\omega)\right|^{2} S_{W}$ is the power spectral density of the free field ground motion applied to the equivalent oscillator. Eq. (29) is used in the following section to determine the urban wave field modified by the waves radiated by each cluster of buildings. 


\subsection{Urbanization effect induced by several clusters}

Once the cluster effect, $\mathrm{H}_{\mathrm{f}}^{c l}(\omega)$, within the ERB, is obtained, the wave field on the surrounding surface ground can be hence determined as depicted in Figure 3. With the aim of developing an analytical model, the propagation of asymptotic cylindrical waves (see, e.g. Morse and Ingard, [21]), from a cylindrical body, simulating an equivalent foundation subjected to a harmonic signal can be determined through the attenuation function $\alpha(d, \omega)$ as follows:

$$
\alpha(d, \omega)=\sqrt{\frac{a}{d}} \exp \left(-\frac{\eta_{g} \omega d}{V}\right) \exp \left[-i \omega\left(\frac{d}{v}\right)\right] \quad \forall d \geq a
$$

where $\mathrm{a}$ is the equivalent radius of the foundation of the equivalent oscillator, $\mathrm{d}$ is the distance between a selected point on the ground surface and the border of the foundation and $\mathrm{V}$ is the velocity of propagation of the waves through the soil of Poisson ratio, $v$, and soil loss factor, $\eta_{\mathrm{g}}$. In the ground surface plane, Eq. (30) can be decomposed into two orthogonal components, as done in Poulos, [25], as follows:

$$
\alpha(d, \omega)=\alpha_{\|}(d, \omega) \cos ^{2} \theta+\alpha_{\perp}(d, \omega) \sin ^{2} \theta \quad \forall d \geq a
$$

where $\theta$ is the angle of the line connecting source and receiver, $\alpha_{\|}$and $\alpha_{\perp}$ are the components parallel and perpendicular to the direction of propagation of the dynamic input, respectively.

Approximate expressions of $\alpha_{\|}$and $\alpha_{\perp}$ can be found in Dobry and Gazetas, [26] as follows

$$
\alpha_{\perp}(\mathrm{d}, \omega)=\sqrt{\frac{\mathrm{a}}{\mathrm{d}}} \exp \left(-\frac{\eta_{\mathrm{g}} \omega \mathrm{d}}{\mathrm{V}_{\mathrm{s}}}\right) \exp \left[-\mathrm{i} \omega\left(\frac{\mathrm{d}}{\mathrm{v}_{\mathrm{s}}}\right)\right] \quad \forall \mathrm{d} \geq \mathrm{a}
$$

in which $\mathrm{V}_{\mathrm{s}}=\sqrt{G / \rho}$ is the shear wave velocity of the soil with shear modulus $G$ and mass density $\rho$, and

$$
\alpha_{\|}(\mathrm{d}, \omega)=\sqrt{\frac{\mathrm{a}}{\mathrm{d}}} \exp \left(-\frac{\eta_{\mathrm{g}} \omega \mathrm{d}}{\mathrm{V}_{\mathrm{La}}}\right) \exp \left[-\mathrm{i} \omega\left(\frac{\mathrm{d}}{\mathrm{V}_{\mathrm{La}}}\right)\right] \quad \forall \mathrm{d} \geq \mathrm{a}
$$


where $\mathrm{V}_{\mathrm{La}}=\left(3.4 \mathrm{~V}_{\mathrm{s}}\right) /[\pi(1-v)]$ is the Lysmer's analogue velocity. Therefore the radiated wave field, $U_{g}^{r}(d, \omega)$, of the homogenized cluster subjected to the seismic motion $U_{g}(\omega)$ is given by

$$
\mathrm{U}_{\mathrm{g}}^{\mathrm{r}}(\mathrm{d}, \omega)=\alpha(\mathrm{d}, \omega) \mathrm{H}_{\mathrm{f}}^{c l}(\omega) \mathrm{U}_{\mathrm{g}}(\omega) \forall \mathrm{d} \geq \mathrm{a}
$$

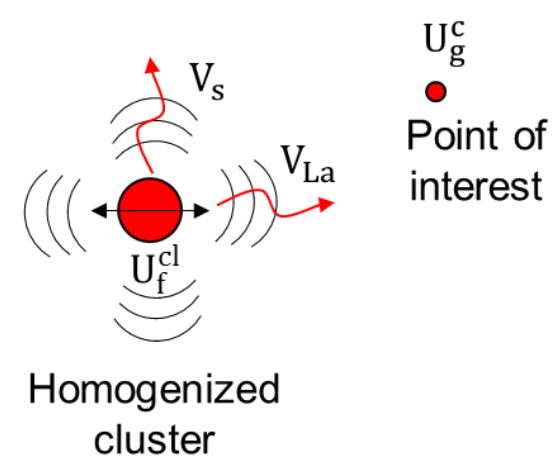

Figure 3 Wave propagation model adopted for this paper.

Therefore, the power spectral density of the radiated wave field, is expressed as follows:

$$
S_{\ddot{\mathrm{U}}}^{\mathrm{r}}(\mathrm{d}, \omega)=|\alpha(\mathrm{d}, \omega)|^{2} \mathrm{~S}_{\ddot{\mathrm{U}}_{\mathrm{f}}^{\mathrm{cl}}}(\omega) \quad \forall \mathrm{d} \geq \mathrm{a}
$$

in which $S_{\ddot{U}_{f}^{\text {cl }}}(\omega)$ is determined in Eq. (29). Moreover, the power spectral density function of the ground motion in the urban environment induced by the radiated wave field of the cluster of building is derived by the following form:

$$
S_{\ddot{U}_{g}^{c}}(d, \omega)=S_{\ddot{U}_{g}}(\omega)+S_{\ddot{U}_{g}^{r}}+S_{\ddot{U}_{g}^{r} \ddot{U}_{g}}+S_{\ddot{U}_{g} \ddot{U}_{g}^{r}} \quad \forall d \geq a
$$

where $S_{\ddot{U}_{g}}(\omega)$ is the power spectral density of the ground surface motion, $S_{\ddot{U}_{\mathrm{g}}^{r}}(\omega)$ is the power spectral density of the radiated wave field, and $S_{\ddot{U}_{g}^{r}} \ddot{U}_{g}$ and $S_{\ddot{U}_{g}} \ddot{U}_{g}^{r}$ are the cross-spectral density functions between the cluster and free field ground motion.

Moreover, In presence of $\mathrm{n}_{c}$ cluster or ERBs considered clusters, only the interaction between one source and one receiver at a time, is considered as done in Poulos, [25] and Dobry and 
Gazetas, [26]. Therefore, the interaction between two clusters of buildings is neglected. This assumption leads directly to the following representation of the ground motion process at selected point within the urban environment:

$$
\mathrm{S}_{\ddot{\mathrm{U}}_{\mathrm{g}}^{\mathrm{c}}}(\mathrm{d}, \omega)=\mathrm{S}_{\ddot{\mathrm{U}}_{g}}(\omega)+\sum_{\mathrm{i}=1}^{\mathrm{n}_{c}}\left(\mathrm{~S}_{\ddot{\mathrm{U}}_{\mathrm{g}}^{\mathrm{c}}}^{\mathrm{i}}+\mathrm{S}_{\ddot{\mathrm{U}}_{\mathrm{g}}^{\mathrm{r}} \ddot{\mathrm{U}}_{\mathrm{g}}}^{\mathrm{i}}+\mathrm{S}_{\ddot{\mathrm{U}}_{\mathrm{g}}^{\mathrm{c}} \ddot{\mathrm{U}}_{\mathrm{g}}^{\mathrm{r}}}^{\mathrm{i}}\right) \quad \mathrm{k}=1, \ldots, \mathrm{n}_{c}
$$

where $S_{\ddot{U}_{g}^{c}}^{\mathrm{i}}(\omega)$ is the power spectral density of the modified ground motion induced by the ithcluster, and $S_{\ddot{U}_{\mathrm{g}}^{\mathrm{r}} \ddot{U}_{\mathrm{g}}}^{\mathrm{i}}$ and $S_{\ddot{U}_{\mathrm{g}}^{\mathrm{c}} \ddot{U}_{\mathrm{g}}^{\mathrm{r}}}^{\mathrm{i}}$ are the cross-spectral density functions between the ith-cluster and free field ground motion, $\mathrm{S}_{\ddot{U}_{g}}(\omega)$.

\section{NUMERICAL RESULTS}

\subsection{Cluster homogenization}

In this section the proposed homogenization approach for obtain the urban effect induced by several buildings is applied. A cluster of $n=1000$ vibrating structures is considered as characterized by a distribution of fundamental periods that, in lack of precise information, are sampled from uniform and log-normal distribution ranging from $T=0.2 \mathrm{~s}(2 \mathrm{~Hz})$ to $T=0.5 \mathrm{~s}(5 \mathrm{~Hz})$ as depicted in Figure 4. Some structural parameters are set to some typical values for conventional buildings (Veletsos and Meek, [27]; Mahsuli and Ghannad, [28]). In the present study, average values of the structural mass, $m_{\text {str }}=450000 \mathrm{~kg}$ and structure to foundation mass ratio, $\beta=$ $\mathrm{m}_{\mathrm{str}} / \mathrm{m}_{\mathrm{f}}=10$, is assumed. The soil domain which material properties are reported in Table 1 , is characterized by average shear wave velocity, $\mathrm{V}_{\mathrm{s}}=200 \mathrm{~m} / \mathrm{s}$, soil damping $\eta_{g}=0.1$ and thickness (h) of 30m. Therefore, from a standard 1D site response analysis (e.g. see, Kramer [29]), the transfer function of the soil deposit, $\mathrm{H}_{\text {soil }}(\omega)$, is given by the following formula:

$$
\left|H_{\text {soil }}(\omega)\right|=\frac{1}{\sqrt{\cos ^{2}\left(\frac{\omega h}{V_{s}}\right)+\left(\frac{\eta g \omega h}{v_{s}}\right)^{2}}}
$$


The soil-foundation stiffness, $k_{\mathrm{SSI}}$, is obtained as the static foundation stiffness for shallow foundation (e.g. see Veletsos and Verbic, [27]) as follows:

$$
k_{\mathrm{SSI}}=\frac{8 G R}{(2-v)}
$$

where the equivalent radius of the foundation, $R$, is assumed as $5 \mathrm{~m}$.

The ground motion at the bedrock is modelled as zero mean Gaussian white noise process with $\mathrm{G}_{W}=0.04 \mathrm{~m}^{2} \mathrm{~s}^{-3}$. The homogenized cluster effect induced by the uniform distribution of buildings of Figure 4a. is depicted in Figure 5a as average cluster effect and in Figure 5b in terms of power spectral density. The charts show the good match between the proposed analytical formulas of Eq. (18) and Eq. (29) and the urban effect induced by the sum of the 1000 buildings. Conversely, for a log-normal distribution of structural frequencies, the cluster effect is different from the homogenized effect obtained from a deterministic linear distribution (Figure 6).

Table 1 Soil properties

\begin{tabular}{|l|c|c|}
\hline Property & Symbol & Value \\
\hline Shear Modulus & $\mathrm{G}$ & $8 \times 10^{7} \mathrm{~Pa}$ \\
\hline Poisson coefficient & $v$ & 0.3 \\
\hline Unit density & $\rho$ & $2000 \mathrm{~kg} / \mathrm{m}^{3}$ \\
\hline
\end{tabular}



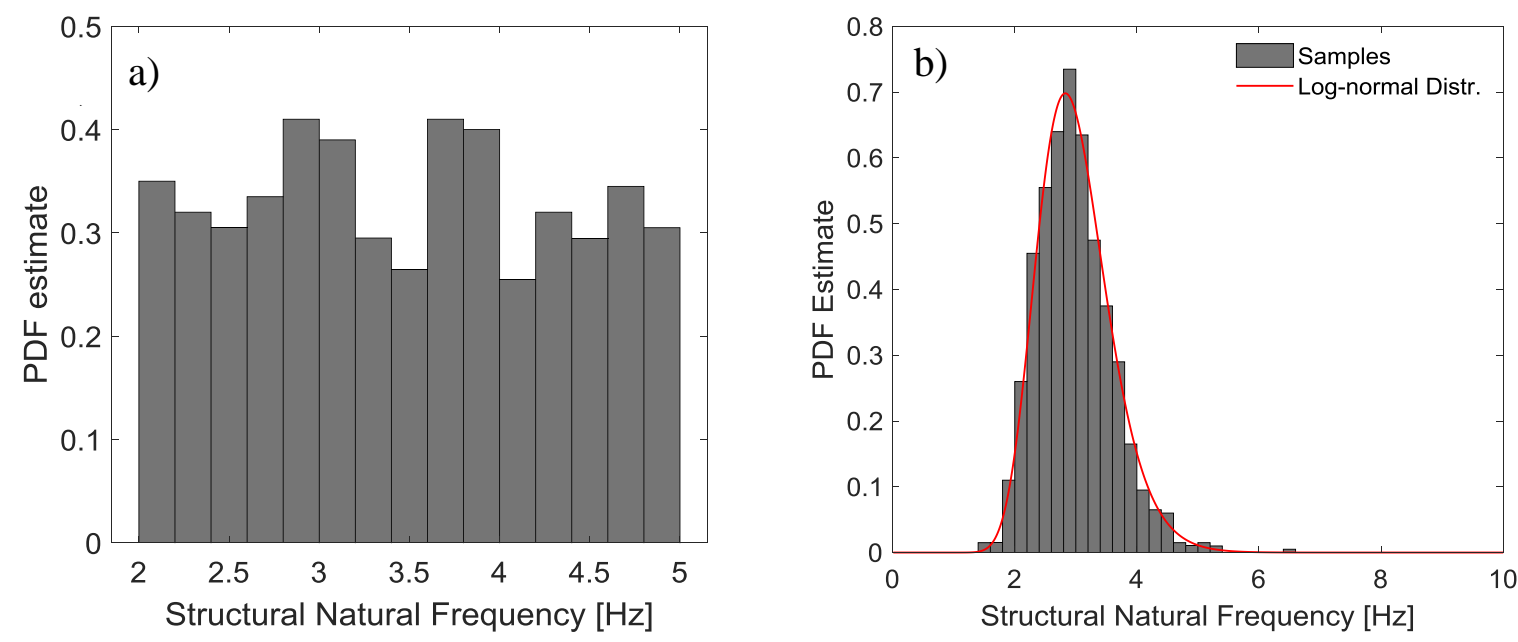

Figure 4 a) Uniform and b) lognormal distribution of 1000 structural natural frequencies in a cluster.
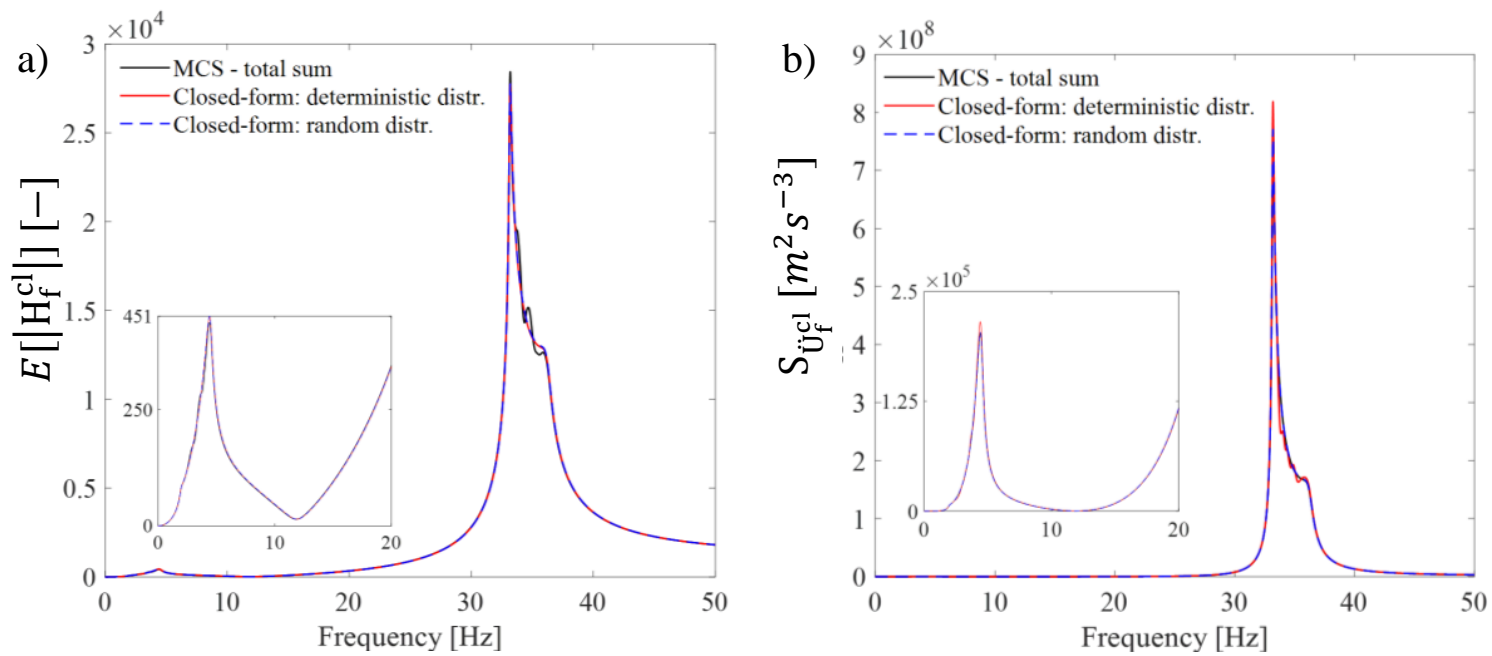

Figure 5 Homogenization of the cluster effect for a uniform distribution: a) average and b) power spectral density. 

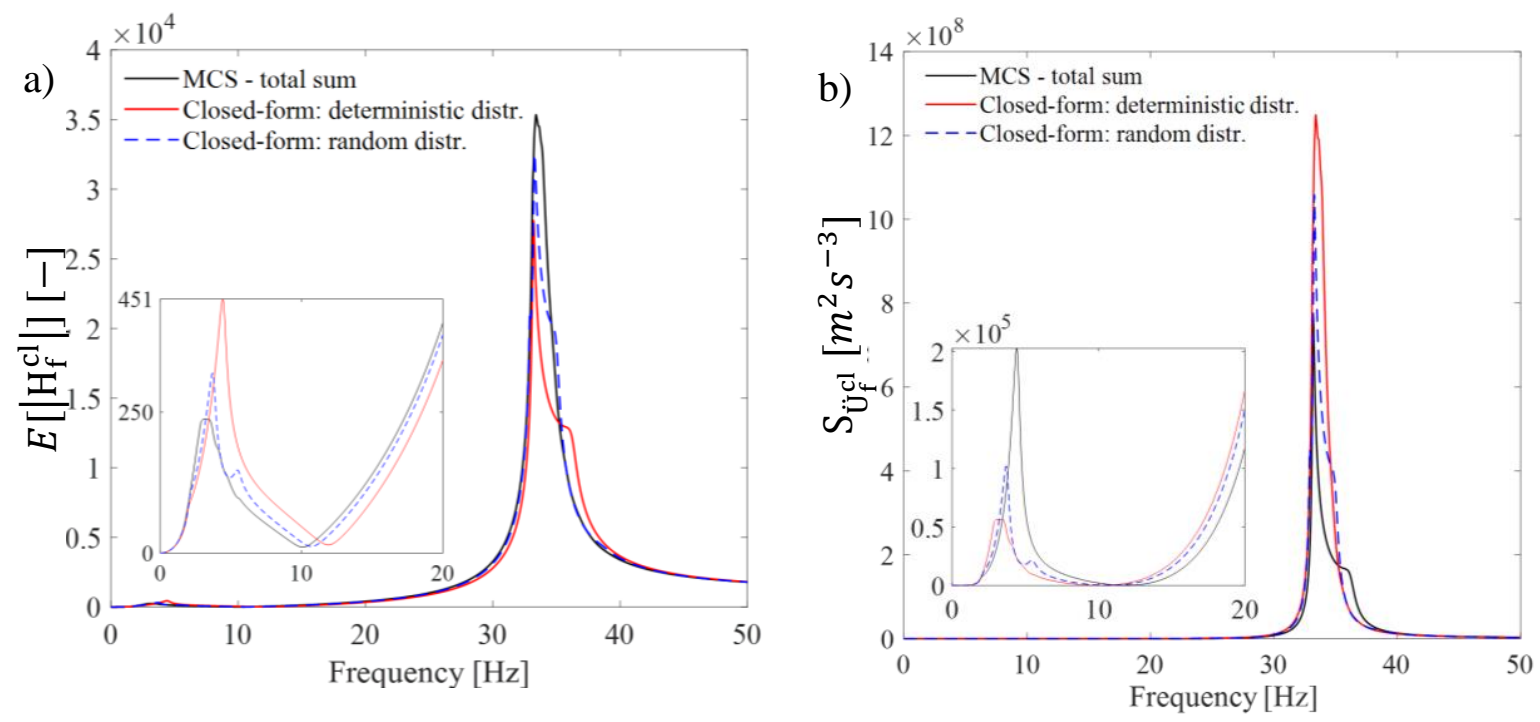

Figure 6 Homogenization of the cluster effect for a log-normal distribution: a) average and b) power spectral density.

By using the proposed analytical formulas of Eq. (26) for the average effect in Figure 6a and Eq (29) for the cluster effect in terms of power spectral density in Figure 6b, this difference decreases and hence, the proposed model can effectively simulates the contribution of $\mathrm{n}$ buildings on the urban environment. The convergence of the results can be improved by using more subintervals, in the current results the distribution of the structural frequencies is divided in $\mathrm{m}=3$ sub-intervals.

\subsection{Urbanization effect around a cluster}

Once obtained the average cluster effect from the proposed homogenization procedure, the urbanization effect can be obtained around the cluster by using the propagation model of Eq. (31). Consider the previous cluster of buildings extended in an ERB of 300m radius. Figure 7 shows the ground surface motion at a distance of $100 \mathrm{~m}$ from the ERB modified by the cluster characterized by a uniform distribution (Figure 7a) and log-normal distribution (Figure 7b) of buildings compared to the free field motion of Eq. (28). 

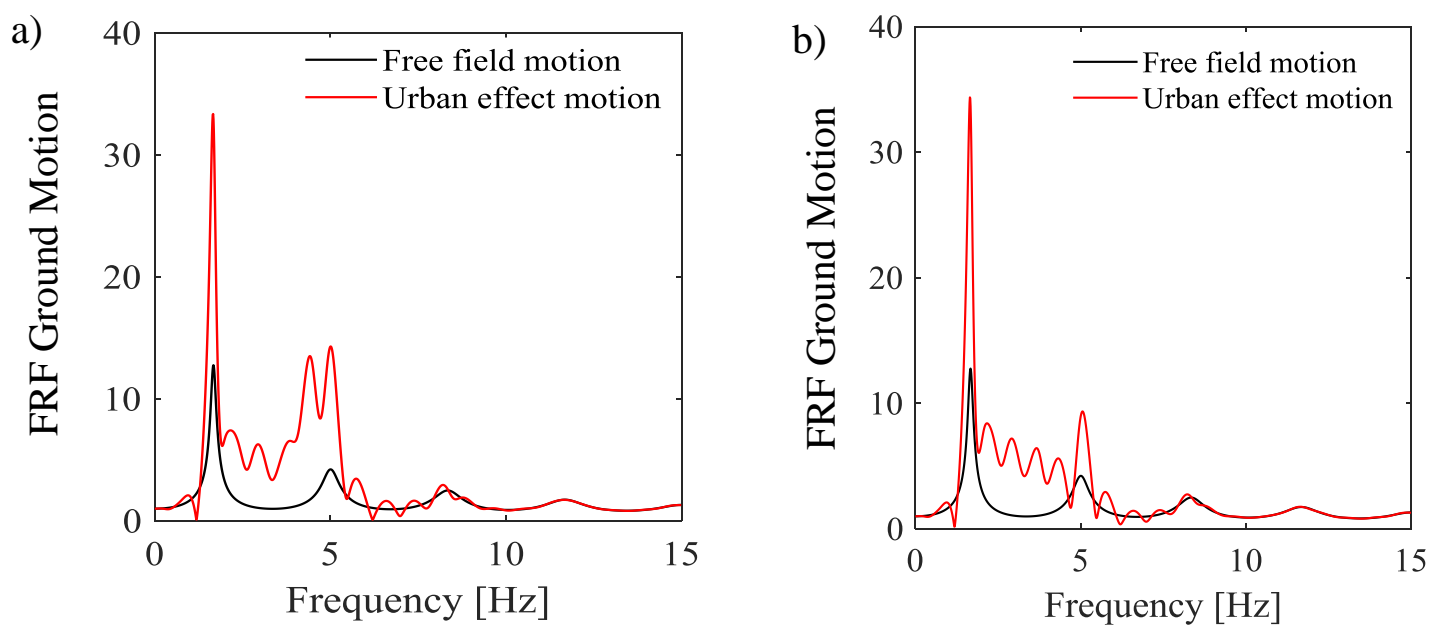

Figure 7 Average urbanization effect in a ground surface at a distance of $100 \mathrm{~m}$ from the homogenized cluster of a a) uniform distribution and b) log-normal distribution of structural frequencies.
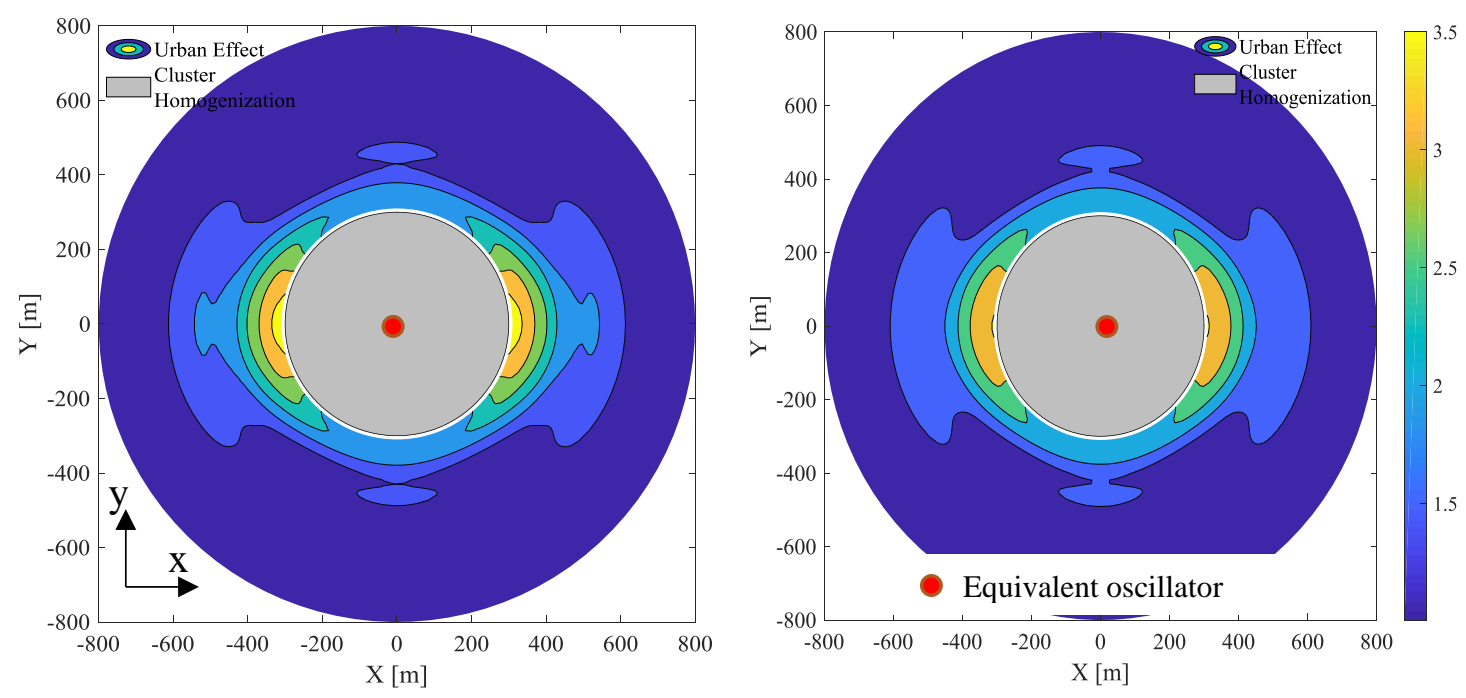

Figure 8 Ratio $\Delta$ of the $50 \%$ fractiles of the peak ground acceleration around the homogenized cluster of a) uniform distribution and b) log-normal distribution of structural frequencies generated by an earthquake directed about the $\mathrm{X}$ direction.

It can be seen that the relevant alteration of the ground motion induced by the urban environment. Finally, the 50\% fractiles of the peak ground acceleration is derived from the power spectral density [30]. Figure 8 shows the ratio $\Delta$ between the $50 \%$ fractiles of the peak ground acceleration of urban effect motion and free field motion in the X-Y plane when an earthquake 
is acting about the $\mathrm{X}$-axis for a uniform distribution (Figure 8a) and log-normal distribution (Figure 8b).

\subsection{Application to a realistic case}

The urbanization effect is studied for an urban areas located in the East Sussex on the northern suburb of Brighton, UK as depicted in Figure 9a. The investigated urban area is divided at mesoscale level in 5 cluster of buildings (Figure 9b) with each radius selected by geometrical considerations according to the distribution of the buildings in the city. For each cluster, the structural period of each building is obtained through the formula proposed by the EN1998-1 for reinforced concrete buildings, $=0.075 H^{3 / 4}$, in which $H$ is the height of the building obtained from the LIDAR map. At the first stage, the homogenization procedure of Eq. (26) is applied to each cluster. Successively, the urban effect around the cluster is obtained by superposition of the single effects as defined in Eq. (36), for an earthquake directed about the $\mathrm{X}$ axis. Figure 10 shows the ratio $\Delta$ between the $50 \%$ fractiles of the peak ground acceleration of urban effect motion and free field motion for the area of interest. It is worth mentioning that around the cluster of buildings, it can be observed areas with an increment of the free field motion more than $200 \%$ as well as reductions of about $20 \%$.
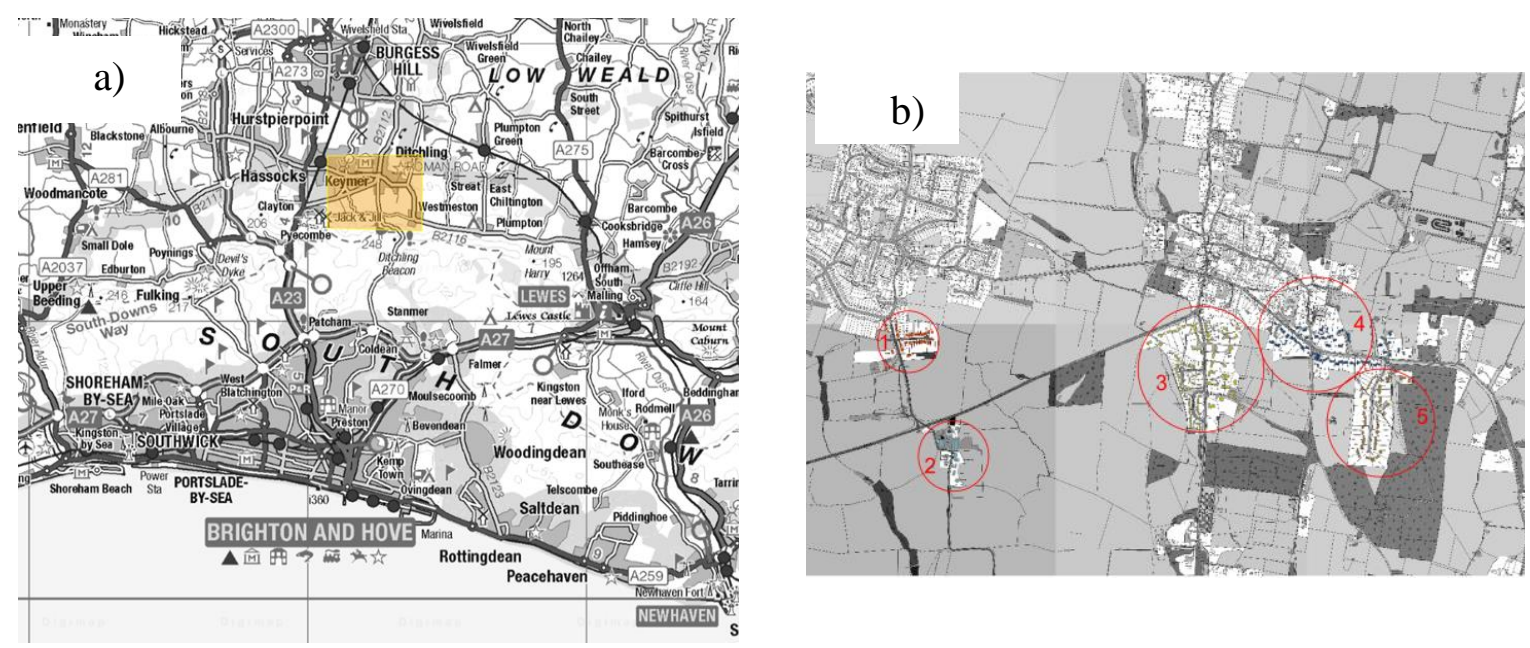
Figure 9 Investigated urban area a) location and b) identification of 5 cluster of buildings.

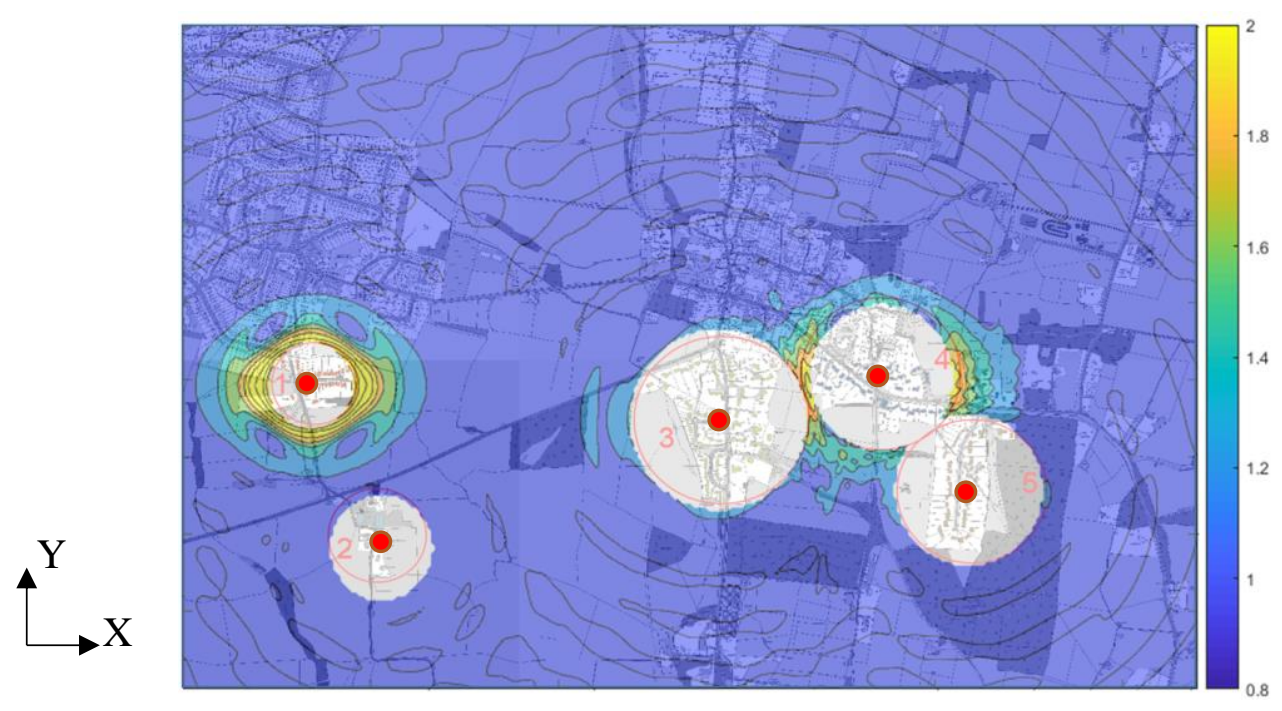

Figure 10 Ratio $\Delta$ of the $50 \%$ fractiles of the peak ground acceleration of the area of interest

\section{CONCLUDING REMARKS}

This paper has presented a hierarchical multiscale approach to define the ground motion modelling in urban areas. At mesoscale level, the vibrations generated by several buildings within a representative region called elementary representative block (ERB) are analyzed through a homogenization approach based on the averaging of the foundation transfer functions of the buildings. Therefore, the transfer function of the cluster is represented by an equivalent discrete lumped model considering soil-structure interaction. Closed-form solutions for any deterministic or random distribution of the structural fundamental frequencies are obtained. At macroscale level, the ground motion in the urban environment is obtained as the superposition of the effects induced by each cluster by means of a cylindrical wave propagation model. $\mathrm{Nu}-$ merical analyses showed the good match between the power spectral density obtained by the proposed formulation and the results of a Monte Carlo Simulation for a cluster of 1000 buildings with uniform and log-normal distribution. Successively, the modification of the free field motion around a cluster is analyzed in terms of 50\% fractile peak acceleration. Results showed 
modifications up to $300 \%$ of the free field motion for large distances. Finally, the proposed framework is applied to a real urban area using data of the buildings from LIDAR maps to demonstrate a practical application of the proposed procedure.

\section{REFERENCES}

[1] G. W. Housner, 'Interaction of building and ground during an earthquake', Bulletin of the Seismological Society of America, vol. 47, no. 3, pp. 179-186, Jul. 1957.

[2] H. L. Wong and M. D. Trifunac, 'Two-dimensional, antiplane, building-soil-building interaction for two or more buildings and for incident planet SH waves', Bulletin of the Seismological Society of America, vol. 65, no. 6, pp. 1863-1885, 1975.

[3] A Wirgin and P.-Y. Bard, 'Effects of buildings on the duration and amplitude of ground motion in Mexico City', Bulletin of the Seismological Society of America, vol. 86, no. 3, pp. 914-920, 1996.

[4] R. Ditommaso, M. Mucciarelli, M. R. Gallipoli, and F. C. Ponzo, 'Effect of a single vibrating building on free-field ground motion: numerical and experimental evidences', Bull Earthquake Eng, vol. 8, no. 3, pp. 693-703, Jun. 2010.

[5] D. Clouteau and D. Aubry, 'Modifications of the Ground Motion in Dense Urban Areas', Journal of Computational Acoustics, vol. 09, no. 04, pp. 1659-1675, Dec. 2001.

[6] M. Kham, J.-F. Semblat, P.-Y. Bard, and P. Dangla, 'Seismic Site-City Interaction: Main Governing Phenomena through Simplified Numerical Models', Bulletin of the Seismological Society of America, vol. 96, no. 5, pp. 1934-1951, Oct. 2006.

[7] Y. Isbiliroglu, R. Taborda, and J. Bielak, 'Coupled Soil-Structure Interaction Effects of Building Clusters During Earthquakes', Earthquake Spectra, vol. 31, no. 1, pp. 463-500, Feb. 2015. 
[8] A. Wirgin, 'Earthquakes in cities revisited', arXiv:1607.08856 [physics], Jul. 2016.

[9] F. Taddei and G. Müller, 'Towards a Nonlinear Discrete Model for Site-City Interaction Through a Sino-European Synergy', in 16th European Conference on Earthquake Engineering, Thessaloniki, 2018.

[10] P. Cacciola and A. Tombari, 'A Ground Motion Model in Proximity of Vibrating Buildings', in Computational Stochastic Mechanics, Paros, Greece, 2018.

[11] P. Guéguen, P.-Y. Bard, and F. Chavez-Garcia, 'Site-City Interaction in Mexico CityLike environments: An Analytical Study', Bulletin of the Seismological Society of America, vol. 92, no. 2, pp. 794-811, 2002.

[12] C. Tsogka and A. Wirgin, 'Simulation of seismic response in an idealized city', Soil Dynamics and Earthquake Engineering, vol. 23, no. 5, pp. 391-402, Jul. 2003.

[13] C. Boutin and P. Roussillon, 'Assessment of the urbanization effect on seismic response', Bulletin of the Seismological Society of America, vol. 94, no. 1, pp. 251-268, 2004.

[14] J. Groby, C. Tsogka, and A. Wirgin, 'Simulation of seismic response in a city-like environment', Soil Dynamics and Earthquake Engineering, vol. 25, no. 7-10, pp. 487-504, Aug. 2005.

[15] M. Ghergu and I. R. Ionescu, 'Structure-soil-structure coupling in seismic excitation and “city effect”", International Journal of Engineering Science, vol. 47, no. 3, pp. 342-354, Mar. 2009.

[16] J. D. Coronado, R. Lomurno, A. Tombari, and P. Cacciola, 'Improving Urban Seismic Resilience through Vibrating Barriers', in ICOSSAR 2017, Vienna, Austria, 2017. 
[17] C. Soize, 'A model and numerical method in the medium frequency range for vibroacoustic predictions using the theory of structural fuzzy', The Journal of the Acoustical Society of America, vol. 94, no. 2, pp. 849-865, Aug. 1993.

[18] M. Strasberg and D. Feit, 'Vibration damping of large structures induced by attached small resonant structures', The Journal of the Acoustical Society of America, vol. 94, no. 3, pp. 1814-1815, Sep. 1993.

[19] L. Friis and M. Ohlrich, 'Simple vibration modeling of structural fuzzy with continuous boundary by including two-dimensional spatial memory', The Journal of the Acoustical Society of America, vol. 124, no. 1, pp. 192-202, Jul. 2008.

[20] L. Friis and M. Ohlrich, 'Vibration modeling of structural fuzzy with continuous boundary', The Journal of the Acoustical Society of America, vol. 123, no. 2, pp. 718-728, Feb. 2008.

[21] P. M. Morse and K. U. Ingard, Theoretical acoustics. Princeton, N.J: Princeton University Press, 1986.

[22] R. Hill, 'Elastic properties of reinforced solids: Some theoretical principles', Journal of the Mechanics and Physics of Solids, vol. 11, no. 5, pp. 357-372, Sep. 1963.

[23] M. Ostoja-Starzewski, 'Material spatial randomness: From statistical to representative volume element', Probabilistic Engineering Mechanics, vol. 21, no. 2, pp. 112-132, Apr. 2006.

[24] D. D. Pfaffinger, 'Calculation of Power Spectra from Response Spectra', Journal of Engineering Mechanics, vol. 109, no. 1, pp. 357-372, Feb. 1983.

[25] H. G. Poulos, 'Behavior of Laterally Loaded Piles: I-Single Piles', Journal of the Soil Mechanics and Foundations Division, ASCE, vol. 97, no. 5, pp. 711-731, 1971. 
[26] R. Dobry and G. Gazetas, 'Simple method for dynamic stiffness and damping of floating pile groups', Geotechnique, London, vol. 38, no. 4, pp. 557 - 574, 1988.

[27] A. S. Veletsos and B. Verbič, 'Vibration of viscoelastic foundations', Earthquake Engineering \& Structural Dynamics, vol. 2, no. 1, pp. 87-102, 1973.

[28] M. Mahsuli and M. A. Ghannad, 'The effect of foundation embedment on inelastic response of structures', Earthquake Engng Struct. Dyn., vol. 38, no. 4, pp. 423-437, Apr. 2009.

[29] S. L. Kramer, Geotechnical earthquake engineering. Upper Saddle River, N.J.: Prentice Hall, 1996.

[30] E. H. Vanmarcke, 'Properties of Spectral Moments with Applications to Random Vibration', Journal of the Engineering Mechanics Division, vol. 98, no. 2, pp. 425-446, 1972. 